\title{
Cultural Dynamics: Omugorogoro And The ‘Culturalization’ Of Hunger Among The Abaluhyia Of Western Kenya
}

\author{
Donald Oluchina Wandere \\ Department of Anthropology, Moi University, Kenya
}

\begin{abstract}
Issues on the interconnections between culture and hunger in general, and the influences the latter impacts on the former in particular, are largely ignored among scholars. When socio-cultural variables relative to hunger are taken as analytical tools, they are more often considered in terms of their independent rather than their dependent value. The reason for this approach is understandable; that the debilitating threat hunger poses on mankind is so urgent and critical, particularly in terms of human morbidity and mortality that it has to be approached in an applied sense, that is, as a phenomenon that warrants a pragmatic approach. This is a preferred mode to that which sees the problem (hunger) as one which may impact on the otherwise "inert", and "inconsequential" human social and cultural behaviour and the institutions therein. This paper discusses the concept of omugorogoro, a figurative term configured and socially institutionalized representation of hunger among the Abaluyia nation of Western Kenya. As a linguistic embodiment categorizing a food deficit situation, the paper argues that the institutionalization of omugorogoro depicts some form of social situation - indeed, a 'lifestyle' among a large cross-section of the rural Abaluyia populace of Western Kenya. Seen in this perspective, hunger assumes a life of its own as an aspect of the culture of the Abaluyia, and with appropriate behavioural accompaniments. The discussions in this paper are mainly based on a study done among the Banyore sub-tribe of Abaluyia, and whose findings are documented in Wandere [13].
\end{abstract}

Key words: Omugorogoro, Abaluhyia, Hunger, Culture, Banyore, Institutionalization

\section{INTRODUCTION}

A reductionist explanation of hunger defines it as a feeling experienced when an individual has desire to eat; the sensation being often alleviated and mitigated entirely with the consumption of food. However, hunger is also commonly used to describe the social condition of people who frequently experience, or live with the threat of experiencing, the physical sensation of hunger. As a social condition, hunger has more often been discussed under the broad subject of famine. Yet, although the two situations are characterized by food deficits, they differ on scale and their impact on the affected population. In their attempt to distinguish between the two, Frankenberger and Goldstein [6] refer to hunger as generally the reduction in dietary intake, while the salient features of famine include the large number of households experiencing extensive social and economic disruptions, and severe and unusual difficulty in obtaining adequate access to food. Famine situations are characterized by mortality rates, starvation and starvation-related diseases. Food and Agriculture Organization (FAO) defines the chronically hungry as people who do not eat enough to get the energy they need to lead active lives. Their undernourishment makes it hard for them to study, work or otherwise perform physical activities [5].

Hunger, seen in its generic sense, is a problem that has evoked considerable interest among scholars, humanitarian and aid concerns, national states, and the international community as a whole. This concern arises from the devastating and enervating effects that hunger, 
particularly in its intensive and extensive forms, causes on human populations. To this extent, pragmatists then talk of urgent transfer of food aid to feed the affected groups, while their theoretical partners, of whom academics constitute the majority, find a perfect study site on which to build assumptions and make causal connections. In the final analysis, evaluations are made on the costs of catastrophe based mainly on the degree of physiological impairment and mortality rates. The beacon stops here. Apart from the analysis on the coping strategies and their risk insurance and management mechanisms, rarely is attention drawn to the long-term implications of hunger on a group's social and cultural formations.

Using the case of perennial hunger among the Abanyole sub-group of the Abaluhyia, this paper argues that sustained cases of food deprivations in a given society may impinge on its sociocultural fabric; the deprivation is "normalized" or "routinized" in the daily lives of the affected individuals and population(s), and with it, a set of emergent behavioural traits and beliefs.

The paper discusses the concept of omugorogoro - part of a systematic naming nomenclature of famine strains - a concept that has now as been embraced and added to the Oluluhyia vocabulary.

\section{POPULATION AND METHODOLOGY}

The following section starts by highlighting a brief ethnogenic background of the study populations the Abaluhyia in general and the Banyore in particular. It then proceeds to discuss the methods used in carrying out the study.

\section{The Abaluhyia People and Economy}

The Abaluhyia - also referred to as the Luhyia or Baluhyia - are a Bantu people, comprising a federation of eighteen sub-groups ${ }^{i}$ that occupies the Western Province of Kenya. People with close linguistic affiliation to Abaluhyia are also found in Eastern Uganda; these include the Bagisu, Banyuli and Bamasaba. Migration stories of the Abaluhyia are not unanimous on their origins. Salient competing arguments do premise their origins to 'Misri', the present Egypt [15], while others tend to associate their roots in Central Africa [2, 8]. Wagner [11], however, suggests that the varied Abaluyia sub-groups had different origins, but majorly from Uganda, West Africa, and from around the Lake Victoria region.

The eighteen sub-tribes of the Abaluhyia are not a closely knit homogeneous unit in as far as cultural and lingual relations are concerned. However, a seamless relationship in culture and language exists among certain sub-groups such as the Wanga-Marama-Kisa-Tsotso; IdakhoIsukha; Marachi-Bakhayo; and the Kabras-Tachoni-Nyala (baNdombi) configurations. The Maragoli and Bukusu stand out as the most populous groups, and bear significant influence on the entire Abaluhyia body-politic.

Traditionally, the Abaluhyia have been known to be agriculturalists, tending to indigenous foods such as sorghum, millet, cassava, sesame, groundnuts and maize. Wagner [11] however states that the Bukusu, though now known to be essentially cultivators, were earlier involved in a pastoral economy - basically as cattle-keepers.

The basic landholding unit among the Abaluhyia has been the extended family. This family essentially comprises the grandparents, the married sons and their families, and the unmarried children. Traditionally, extended family members built their homes on the same piece of property, but each elementary family cultivated its own field. Each of these elementary families constituted a consumption unit in its own right, and in this regard, it is defined as a household. Rights over land ownership were established either by inheriting a piece of the grandfather's 
land, being apportioned a piece by one's father, or by cultivating a piece of virgin land. In addition to these plots owned by individual families, there used to be some sections that were under the control of the clan head. A part of this land served as a communal grazing ground for all members of the clan. Another part was traditionally held in reserve and in times of need could be allocated by the head to individual clansmen whose property this land became after they had first cultivated. With the 1955 Swynerrton Plan that ensured land consolidation, adjudication and registration in the names of individual titles in Kenya, this trend has now become history.

The traditional tenure system of the Abaluyia favours male children who would, ultimately, receive an equal or nearly equal share of the family land and cattle. If a man died before his sons inherited his property, one of his brothers acted as a trustee until the sons came of age. If a man had no direct descendants, his brothers or their sons inherited his property.

From a traditional perspective, the social and dejure relationship between a luhyia (a person of Abaluhyia descent) husband and his wife was ill-balanced. Traditional customs and conventions were defined to prejudice against the wife's status:

"....she has no ownership status whatsoever ...she has no right of ownership to any object she handles...she has no right to dispose of any of these objects unless she acts upon her husband's instructions... she has no right over her children in her quality as the mother...she has no legal independence or individuality..." [11: 13-14].

Though seemingly overstated, Wagner's contention, above, brings forth the asymmetrical power relations that existed between men and women among Abaluhyia.

The traditional division of labour among the Abaluhyia is in many aspects akin to that of other agricultural communities. Yet again the heavier burden here lies with the wife who has to clean the house and the cattle section, fetch water, collect firewood, cook and look after the children. The greater part of the planting, weeding, and harvesting is also done by her. The husband, on the other hand, has certain duties of construction of the house and looking after cattle and other livestock, and is responsible for all other transactions concerning the transfer of livestock in kinship relations. Children are trained at early ages to share the duties of the family life; boys begin to herd small livestock (e.g. goats, sheep) and later on cattle. Girls assist their mothers in the daily work of fetching water, gathering firewood, foraging vegetables, grinding millet and sorghum, etc.

The shift from economic self-sufficiency within the traditional family to dependence on the market economy has affected both the division of labour and the social cohesion. Where commercial crops are produced, women have to bear the heavy burden of extra work in tending to the crops, while men go comparatively idle - particularly so because their former duties of hunting, cattle raiding and protecting the herds have through time been rendered irrelevant. On social cohesion, the effects results from the flux in search of employment (more so among the male members) that subsequently lead to a separation in family lives.

\section{Banyore}

The Banyore (also referred to as Abanyole), arguably, the most densely populated sub-group of the Abaluhyia, constituted the study population in this research. The Banyore are inhabitants of an area referred to as Bunyore, or locally, Ebunyole; an area that is within the administrative districts of Emuhaya and Luanda. The two districts are surrounded by Abashisa, Abalokoli, and Abetakho - all sub-groups of Abaluyia, and to a greater degree, the Nilotic Luo (Abanyolo) tribe. Although the relationship between Banyore and their neighbouring Abaluyia sub-nations is 
generally amicable, on the other hand, owing to long historical misunderstandings over boundaries particularly in areas around Maseno, their association with the Luo has largely been frosty.

Just like in the case of the rest of the Abaluhyia sub-groups, there is no consensus yet by researchers and scholars on the actual origins of Banyore. However, it is generally believed that, from wherever they had originated (probably in Misri, Egypt), the fore parents of Banyore exited at the shores of Lake Victoria. They then travelled to Kit Mikayi near Kisumu, before sojourning at a place called Esianganyinya in the present Wekhomo Location. It is from Esianganyinya that Banyore spread out to other parts of the current Ebunyole region. Gideon Were [15] on the other hand, suggests that the ancestors of Banyore may have hived out of the Banyole (Bunyuli) of Eastern Uganda. They then travelled through Kadimo, to Sakwa and to Akala in Nyanza Province, before settling in Ebunyole.

The genealogy of Banyore is traced to one, Anyole son of Mwenje. Anyole is said to have had several sons, among them being Amutete, Asiratsi, Amang"ali, Andongoyi (Tongoyi), Asiekwe, Asakami, Amuli, Mwiranyi, Ambayi, Asikhale, Amuhaya and Muhando. These sons had different mothers. Nowadays, the term Anyole is often invoked in a camaraderie manner by Banyore in reference to "one of our own"; a kinsperson.

One of the main characteristics of the Banyore community is their salient clan differentiations; with the clans named after the sons of Anyole. Not only has this influenced the politics of the day in Bunyore, but it too has led to chauvinistic and disparaging feelings and attitudes among member clans. Gideon Were [15] makes reference to twelve clans that are found among Banyore. Among the prominent clans here are the Abasiekwe, Ababayi, Abakhaya, Abasikhale, Abasiratsi, Abamuuli Abamutete, Abamang'ali, Abatongoi, Abasakami and Abamutsa. Aba- in this context refers to "those belonging to-". The clans are, in this case, traced to the sons of Anyole.

\section{METHODOLOGY}

Discussions in this paper are based on a larger study undertaken among Banyore living in their indigenous locale of Emuhaya district (Ebunyole), and those in the Lugari Diaspora. The study focused on the effects of seasonal hunger - that commonly characterizes Emuhaya - on the socio-cultural value systems of Banyore living in Ebunyole. The Diaspora group was picked for comparative purposes. They were considered much more food sufficient and, as a matter of fact, the chief sources of food and cash remittances to those back in the 'reserves' or locally, risafu (read, Ebunyole). The Diaspora in Lugari had emigrated here beginning the mid 1960's as a result of land and population pressures in Ebunyole. In a study carried out between 1934 and 1938 in Ebunyole, Gunter Wagner alludes to a region with heavy population pressures at the time;

"In the chieftaincy of Bunyore it reaches the remarkable figure of 1,137 persons per square mile. In these parts the native homesteads stand close together, every inch of arable soil is exploited to the utmost, and the pasture land is so scarce that not only sheep but also cattle are tethered while grazing or even stable-fed. But even the extraordinary fertility of the soil and the two full crops which it yields every year cannot sustain such a dense population." [11: 15].

In this study, core anthropological methods that included key informant interviews, focused group discussions, informal interviews, and the observation method were utilized in the collection of data. Data on households was collected by use of questionnaires, through the survey method which targeted 300 households - of whom 200 were from Emuhaya, and 100 from Lugari. Emuhaya has a population density of 933 persons per square kilometre against a 
national average of 230 persons per square kilometre. This makes Emuhaya one of the most densely populated areas in Kenya. Etambale et.al [4] says that at least 20 per cent of the residents in Emuhaya District are landless. This has resulted in a high poverty level of over 60 per cent, and a soaring crime rate.

The study was driven by three theoretical perspectives. First, was the Historicalism associated with the German-Jew, Frans Boas. In the light of Historicalism, the study looked at the sui generis or subjective spheres of culture whose 'limiting factor', according to Boas, were an environment's physical features. The environment, he says, has the capacity to extract the kind of cultural development which may take place within a particular milieu [1]

The second theoretical model, and which is closely related to the above, was the Environmentalism linked to Roy Ellen. Ellen says that environmentalism is applied to an explanatory scheme, which maintains that human social and cultural behaviour is to a large extent determined, in a mechanistic fashion, by the natural habitat. The 'cultural area' concept of Otis Mason and Friedrich Ratzel [7], suggesting that man's habitat is presumed to delineate certain social and behavioural particularities, is also linked to Environmentalism. In our case, the theory will assist us decipher omugorogoro as a cultural situation that is greatly influenced by Bunyore ecosystem.

Finally, William Thomas' [16] Definition of the Situation was instrumental in guiding the study on areas to do with choice and decision-making by the population, particularly in reference to the Banyore emigrants who left Ebunyole for Lugari. This theory has its basis in the motivation behind an individual's behaviour and behavioural change.

\section{FINDINGS AND DISCUSSIONS}

This section sets out to conceptualize omugorogoro as both a functional and symbolic term. It then gives a history of hunger among the Abaluhyia from the turn of the $20^{\text {th }}$ century to the most recent case. The section then ends with a discussion on how omugorogoro as a depiction of hunger, has been entrenched and assimilated in the Abaluhyia culture in general, and among Abanyole in particular.

\section{Omugorogoro: Concept and Use}

Omugorogoro/omukorokoro/mukorokoro/gorogoro as variously referred to, is a term whose linguistic origins are not clear. The word has no definite Luhyia roots, but has been associated with the Luo and Teso ethnic groups at one point or another. In the recent times, the usage of the term has gone beyond the western region of Kenya and is now adopted by among other tribes, the Kalenjin, Pokot and Turkana. In its application, particularly among the Abaluyia, omugorogoro has dual meanings. In the first instance, the term was originally used in reference to a two-kilogram metal containerii used as a unit of measuring foodstuff, particularly cereals, in the open markets. The use of this container mutated from an earlier one, indubi, a basket woven with reeds and smeared with cow-dung in the inside in order to seal it from leakages.

Secondly, and more pertinent to our discussions, omugorogoro has been used symbolically as embodying a situation of food scarcity. In this case, it bears the same meaning and is used interchangeably with inzala, the actual Luhyia word for 'hunger' - an absolute reflection of food deprivation. Henceforth, the term omugorogoro has now been entrenched in the Luhyia lingual with the explicit meaning of food insecurity. Quite commonly among the Abaluhyia, the word is invoked in everyday salutations to express one's physiological status in as far as food want is concerned. The conversation may take the following cue:

Member 1: Orie owefu? (How are you one of our own?)

Member 2: Endi omulamu...omugorogoro kwonyene. (Am fine...just the hunger ravages) 
The response by Member 2 can be interpreted as either as a statement of status information, or as a clever but guarded way of alms seeking.

\section{Hunger in Western Kenya: A chronology}

Experiences of food deprivations are not new among the Abaluhyia of Western Kenya. However, the frequency with which hunger occurs - year in, year out - is considered a much more recent phenomenon. In a popular Luhyia vernacular FM station in Kenya, Mulembe FM, a mid-morning interactive call-in program is aired on weekdays. The program, metaphorically dubbed tinya nende omugorogoro (translated to state, "Be resilient in the face of hunger"), seeks to find out how the listeners are coping with hunger. The fact that this program is aired throughout the week and all year round, without taking cognizance of the agricultural season or food situation of the day, is in itself a powerful statement. It is a grim indication that the Abaluyia are a people that perennially experience hunger situations.

As to when the rain started beating the Abaluhyia in respect to hunger, has in itself been a subject of debate. Wagner [11] for example, in reference to the Banyore of the 1930's, states that the dense population at the time did not mitigate for an ample food security situation. Hence, cases of hunger were commonplace then. On the other hand, Maxon [9] suggests that before 1943, the Banyore and Maragoli were generally food sufficient in the extent to which they actually delocalized foodstuffs to other regions. The mode of subsistence pursued by the early Abaluhyia included hunting, cattle keeping and farming. The benefits of vast land and a sparse population among a large cross-section of the Abaluhyia then ensured that they acquired as much food as possible.

In the colonial times, the commoditization of land as private property - through the process of consolidation, adjudication and registration - individualized possession and placed limitations on ownership. This was sealed through a Land Act - the Swynerrton Plan of 1955. The implication of this policy was that land would cease being the preserve of the collective - the clan or lineage - but instead, be property to be registered in an individual's name. Hence, space became an issue in the subsistence of families as boundaries were now clearly demarcated. The traditional tenure system, which defines inheritance of property in the names of the sons of the lineage leading to sub-divisions of individual family land, is, arguably, the genesis of land problems amongst Abaluhyia. With generation after generation laying claim on the same constrained parcel of land, demand for this important resource would in the end be outstripped by an ever expanding human population.

Prior to this, incidences of critical food scarcities can still be recollected. Basically, there is no clear distinction between the terms 'famine' and 'hunger' in Luhyia language. Both are referred to as inzala/enjala. The history of famine and hunger in Western Kenya reveals a systematic form of nomenclature where deprivations are given names based on certain prominent events of the day, and in other cases, the major features that characterize a particular famine or hunger strain. The earliest season of serious deprivation recalled, occurred at the dawn of the twentieth century. Among the Banyore, Kisa and Marama sub-groups, this strain of hunger was referred to as Inzala eya Mutumbu. During this period, men and women from the said subgroups travelled to Luoland to provide labour in exchange for food (an exercise locally referred to as okhusuma). Though the origin of the name Mutumbu is not quite clear, it could possibly be in reference to a Luo place going by the same name, and which is located in Gem - along the Kisumu-Busia highway. Presumably, it is in Mutumbu that members of the Abaluhyia sought food in exchange for labour. 
Inzala eya Opande followed around the year 1914. The term Opande could have been a local corruption of the Swahili name Kipande; a system of governance introduced by the British Colonialists at more or less the same time, and which was meant to vet the movement of the male African population involved in migrant labour. Kipande, in itself, was an identification document that was inserted in a metal container, and hang around the neck of the wearer. The behavioural trajectory surrounding the Kipande system was greatly disdained by Africans as it tended to equate male Africans adorning this object with the White settler dogs that were commonly strapped with leather strips around their necks. Indeed, in the later years, this was to become one of the major issues in the quest for self-determination by the Africans. The Kipande is the precursor of the existing national identity card, an item for identification that should, by law, be possessed by every adult Kenyan citizen aged eighteen years and above.

Inzala eya Opande was followed closely by Inzala eya Keya, an affliction associated with the First World War of 1914-1918. At about this time, Africans were being forcibly conscripted to serve in the Kings African Rifles (KAR) alongside the British Army. It was claimed that Inzala eya Keya occurred because locally produced foodstuffs were being rerouted to feed servicemen involved in the war. Keya was the corruption of the acronym KAR.

In 1942/43, one of the most severe and well- known food calamities struck the Western region of Kenya and beyond. Thought to be one of the harshest periods of food deprivations, the famine - named Inzala eya Eshikombe - was characterized by a shift in the manner in which foods were measured for commerce or exchange by Abaluhyia. Traditionally, a small container called akhakhunji or a larger version of the same, indubi, were used as units of measuring foodstuff. Due to food scarcity during the Inzala eya Eshikombe famine, foodstuff was measured in a cup (eshikombe) - smaller in size than akhakhunji, but given an equivalent economic value.

According to Maxon (2003), the 1942/43 inzala eya esikombe famine marked a significant watershed in Banyore's (and Abalogoli's) transformation from being a food sufficient community to one of being deficient. This, according to him, is the period that this region started experiencing food deficits. Before then, the area was a leading producer of maize for sale in Western Kenya, a situation associated to market factors, state action, and changing dietary patterns among the residents. The popularity of maize here was mainly attributed to the efforts by the then Provincial Commissioner of the North Kavirondo, John Ainsworth.

During Ainsworth's time, administrative officers distributed Hickory King Variety of maize seeds, which quickly superseded previously grown varieties. It is around this period that maize became a staple food crop in the region. According to estimates, households in the area consumed $92 \%$ of all the maize consumed in North Kavirondo. This resulted in significant alteration of traditional cropping patterns. It is therefore around this time that maize meal (obusuma) became the staple food of the inhabitants here.

After the Inzala eya Eshikombe, other lesser severe strains of deprivations occurred. For instance, around 1952/53 at the onset of the guerilla liberation war against the colonialists and fronted by the Kenya Land and Freedom Army, aka Maumau, there occurred hunger that was christened Inzala eya Maumau. Yet again, in 1961, severe drought that resulted to acute food shortage occurred in Luhyialand and its environs. This was shortly followed in 1962 by enormous flooding - a situation necessitating the distribution, by helicopters, of an imported caliber of yellow maize. And in the period trasversing 1973/74, at the transition from the British system of measurement to the current Metric system, there occurred yet another hunger strife aptly christened Inzala eya Kilo (after the Metric Kilo). 
Then in early 1984 came Inzala eya Omugorogoro - the term omugorogoro now trending and entrenching itself in the day to day oluluhyia lingua and synonymously used in reference to hunger or famine. In the same way that participants in the Inzala eya Eshikombe used a cup (eshikombe) as a unit of measure in place of akhakhunji, so did those in Inzala eya Omugorogoro use a two-kilogramme container of the then popular Kimbo and Cowboy brands of cooking fat as measures of quantity. To this moment, these containers are the most popular measuring units of grains and other cereals in market places and homes. In this study, 97.5\% of the Ebunyole respondents in the household survey would use omugorogoro for measurements, whether within their homes or at the market places.

As a figurative term for hunger, the word omugorogoro is now used generically for all strains of hunger subsequent to the initial deprivation of 1984. The depth of this entrenchment in the Luhyia vocabulary is exemplified by the very fact that, currently, the term omugorogoro is conceptually easing out inzala in the reference to hunger or famine. For instance in Bunyore in the year 1996, there was what was referred to as Omugorogoro okwa Saba Olulala, (translated to mean 'a season of hunger characterized by borrowing food only once'), rather than what would have been previously Inzala eya Saba Olulala. At the time of fieldwork, Kenya was experiencing a serious food crisis as a result of poor food output, a situation associated with the early 2008 post-election violence. In Luanda, two terminologies were then competing in the christening of this particular food crunch: the first being Omugorogoro okwa Obama while the other was Omugorogoro okwa Bamba 80. Since nomenclature is done relative to major events, the choice of the first name has to do with the installation of Barack Obama - a man of Kenyan heritage - as the president of America in January 2009. The second term relates to the retail price of one 2 kilogram tin, gorogoro, then costing KShs. 80.00 (about \$1) - an astronomically high figure for the average Kenyan, hence constraining access to this staple food.

The following tabulation represents the salient hunger periods experienced by Abanyole from the early $20^{\text {th }}$ century.

\begin{tabular}{|c|c|c|}
\hline Period & $\begin{array}{l}\text { Name of hunger } \\
\text { strain }\end{array}$ & Main features \\
\hline $\begin{array}{l}\text { Early } \\
1900 \text { 's }\end{array}$ & $\begin{array}{l}\text { Inzala eya } \\
\text { Mutumbu }\end{array}$ & $\begin{array}{l}\text { Abanyole travelled to Luoland to offer labour in exchange } \\
\text { for food (Okhusuma). }\end{array}$ \\
\hline 1914 & Inzala eya Keya & $\begin{array}{l}\text { Africans were being forcibly conscripted in the army during } \\
\text { the First World War. }\end{array}$ \\
\hline 1920’s & Inzala eya Opande & $\begin{array}{l}\text { Coincided with the introduction of the kipande system of } \\
\text { identification by the colonialists. }\end{array}$ \\
\hline $1942 / 3$ & Inzala eya esikombe & $\begin{array}{l}\text { A cup, in place of the traditional baskets, was used a unit of } \\
\text { measuring cereals. }\end{array}$ \\
\hline $\begin{array}{c}\text { Mid } \\
1950 \text { 's }\end{array}$ & Inzala eya Maumau & Coincided with onset of the Maumau guerrilla warfare. \\
\hline $1973 / 4$ & Inzala eya kilo & $\begin{array}{l}\text { Coincided with the change to the metric system of } \\
\text { measurements. }\end{array}$ \\
\hline 1984 & $\begin{array}{l}\text { Inzala eya } \\
\text { omugorogoro }\end{array}$ & $\begin{array}{l}\text { Characterised by the introduction of a two kilogramme tin } \\
\text { (gorogoro) unit of measure. }\end{array}$ \\
\hline 1996 & Saba olulala & The clarion then was 'beg (for food) only once'. \\
\hline $2007 / 8$ & Bamba 80 & $\begin{array}{l}\text { The peak price of one gorogoro of maize was KShs } 80.00 \\
\text { (about \$1). }\end{array}$ \\
\hline
\end{tabular}




\section{Omugorogoro: It's Institutionalization and 'Culturalization'}

The foregone conversation presents a staggered experience of salient hunger situations among the Abaluhyia from the beginnings of the $20^{\text {th }}$ century to the early $21^{\text {st }}$ century's Bamba 80 . In between these, were less severe and more tolerable forms of the deprivation. With time, and responding to the ever expanding population against a constant land size, these strains of hunger became frequent and predictable - hence seasonal. Dreze and Sen [3] refer to such dietary adjustments as informal security systems. It is within such periods that, for the most vulnerable, hunger really bites. In the study, $45 \%$ of the respondents in Bunyore admitted to experiencing periods of food deprivations year in, year out. According to a majority of the respondents (76\%), the first quarter of every year constitutes the major threat to food security for the Abanyole and by extension, Abaluhyia at large.

For this lot, maize harvesting for the first season (erotso) is done around the months of July/August. Prior to this time, and around the month of June, beans - which cushion the food base of most households and is considered a transitional crop towards the season of plenty would be ready for consumption. Thus, from around June to August, Luanda witnesses a surge in the availability of farm foods. The harvested crop, though meager as a result of small farmlands coupled with poor agro-systems would, among most households, be ample enough to satisfy basic food needs. Prices of staple foods are also stabilized by the availability of the harvested crop. In addition, the second maize growing season (esube) that commences around September helps to boost the food security situation through to the onset of the following year. After the exhaustion of the esube maize crop, omugorogoro creeps in. This cyclic pattern is repeated each year.

The respondents in Bunyore who acknowledged to experiencing hunger on a yearly basis $(45 \%)$, also stated in their entirety that to them, the malaise was a destiny and there was no way in which they could disentangle from it. The Abanyole have now integrated it as an acceptable reality of their social world and hence institutionalized this phenomenon as a normal happening. The implication of this on the social body of the Abanyole is far-reaching: the feeling of fatalism and helplessness is slowly creeping in and gradually being encultured within Abanyole ethos. This fatalistic attitude does not augur well for the cultivation of a positive environment that can disengage Abanyole from the chains of hunger. Hunger, in this case, is boxed into the social life of the people. A parallel to this situation can be drawn from Oscar Lewis's "culture of poverty" among slum-dwellers. According to Lewis [10], once the culture of poverty comes into existence, it tends to perpetuate itself. In such cases, people are psychologically unready to take advantage of the changing conditions or improving opportunities that may develop in their lifetime.

The fact that a significant proportion of respondents, apparently, have surrendered themselves to the mercies of the scourge implies that the perpetual occurrence of hunger is impinging on the national character of the Abanyole. Lewis's [10] study on the culture of poverty among slum-dwellers points out that by the time the slum children are six or seven years, they usually would have absorbed the basic attitudes and values of the poverty sub-culture. This paper suggests that this contention by Lewis could actually be applicable in the Abanyole case. The spirit of economic aggrandizement that hitherto epitomized a community abundant in food is now caving in to a demoralized lot that is characterized by a fatalistic, helpless and apathetic attitude - attitudinal elements that may be inculcated and internalized right from childhood. The internalization of such thoughts is negative to the psyche of the affected population as it definitely inhibits innovative efforts channelled towards breaking away from this seeming vicious circle. This, thus, sees the making of a hunger sub-culture. 
In the study, it was hypothesized that hunger does not operate in a vacuum; its victims are individuals who are held together by definite cultural fabrics whose porous nature may be influenced by the affliction. In such a situation, the tenacious nature of the ethos, norms and values of the affected population are greatly tested by the effects of the hunger ravages to the extent that the cultural body succumbs to emergent opportunistic traits hitherto non-existent. In this regard, previous traits yield to new socio-cultural forms that can be linked to situations of food deprivation, thereby propelling the dynamic wheels of culture. As an institutionalized social phenomenon, omugorogoro and associated behavioural characteristics are thus entrenched in the cultural spine of Abanyole and Abaluhyia as a whole.

Culture is a social heritage, a largely subscribed attribute and habitual behaviour, among its other elements. In addition, culture is not static, it is dynamic - the field of cultural dynamics usually involves the study of culture within a time frame. Hence, approaches on culture dynamics are often done from a diachronic perspective. Franz Boas' 'historicalism' seeks to look at the interrelationships between past experiences and current cultural traits among groups. He suggested that each culture has its own unique history that gives a particular character to traits currently observed. This is part of what contributes to making cultures autonomous, or what Boas refers to as the sui generis nature of culture. The 'culturalization' of omugorogoro among the Abanyole should therefore be contextualized within the dynamic nature of culture. In the conceptual modes of the Abanyole, there are certain specific behavioural trends and mannerism that can be singled out and be directly linked to recent hunger situations. To them, the ravages of hunger result into certain unconventional behavioural patterns or observations that were previously absent. In addition, other forms of traditional adaptations to food deprivations may also be modified to suit new situations.

One of the objectives of the study was to identify emergent social and cultural traits as a result of conditioning through experiences of perennial hunger. It further sought to understand the extent to which the traits were integrated and welded into a continuous unfolding cultural process. This, indeed, is the content within which the concept of omugorogoro is 'culturalized'. For instance, the institution of a reciprocal relation locally referred to as okhusuma seems to have acquired new meanings.

Conventionally, okhusuma was considered a form of social support mechanism whereupon members of the Abanyole and other Abaluhyia communities who experienced irredeemable food constraints would provide labour in anticipation of being given cereals or other foods in appreciation. Therefore, for the lot that was disadvantaged in food sufficiency, the institution of okhusuma provided a lifeline. Typically, an individual who goes okhusuma would rise up in the wee hours, go to the targeted farm (omukunda), and without knowledge or permission from the farm-owner, undertake any necessary work on the land. Somehow, the owner comes to know about the presence of the 'stranger' on the omukunda and out of 'sheer embarrassment', gives the person some foodstuff as a way of appreciating. It is like a rehearsed act, yet a very significant symbolic gesture of reciprocity.

The other version in the reciprocal relations is more profit-oriented. It involves lending food (okhuhambia) to an individual in dire need by one with abundance. Although trust is the binding factor in this transaction, the issue of security or credit worthiness implicitly plays a role here.

Characteristically, the person in need visits the lender to-be, where he/she puts his/her request. The latter asks for time to consider the proposal. In the meantime and in a clandestine manner, he/she makes investigations on the ability of the applicant to repay the requested 
foodstuff by say, checking on the production potential of the crops grown by the will-be borrower, or counterchecking with individuals that he/she may have borrowed from before. This acts as security. Satisfied on the capability of the person to repay, the prospective borrower is sent for and a verbal agreement is entered. The amount of food borrowed is measured in a basket (esimwero). An empty smaller basket (indubi) in which the agreed additional foodstuff will be put when returned, ostensibly as interest (injeresio), would then be placed on top of the borrowed stuff - symbolizing the surplus value. In order to keep at arm'slength other prospective borrowers (as this would usually be a period of food scarcity), this transaction would be undertaken at dusk. Watts [14] enumerates a more or less similar scenario of borrowing food among the Hausa of Nigeria.

As has already been stated here, traditionally, okhusuma was some form of social reciprocity measure meant to cushion the hungry by providing them with food in exchange for unsolicited labour, and without overt economic motive. This implied that the hungry are taken care of using certain socially accepted modes of exchange that are devoid of criminal activities. Other socially accepted forms included obligatory rules that required better off relatives to support those in need. Mothers and children in particular would be handed food tokens when visiting certain kinspersons, such as mother's brother (maternal uncle). Walker [12] underlined the extensive application of the strategy of children moving in with the elderly as part of coping mechanism in times of hunger among certain communities. These socially sanctioned reciprocal relations were clearly distinguished from others such as okhusaba (begging); behaviour considered more of a vice and hence frowned upon. Okhusaba stood for an extreme dependency character and thus portrayed such individuals negatively - as a worthless layabout. But in the current situation where resources and opportunities for economic empowerment are fast diminishing, okhusaba based on reasons to do with hunger is becoming more of a norm. Okhusaba may manifest in various forms. First, it may take the form of blatantly begging for cash or food in market places and homes. In such cases, in order to evoke sympathy, the beggar justifies his/her behaviour by using hunger as a reason or excuse. For instance, the ostensible reason could be self-centred as in the beggar seeking alms for personal food needs (e.g. endi inzala omwana wanje - translated to mean 'I am hungry, my child') or, it could be on behalf of the more vulnerable and empathetic lot, children in particular (abaana bakonile inzala - meaning 'The children slept hungry').

Alms seeking would also take the form of a more indirect manner that is characterized by telltale innuendoes. In such a case, a common terminology in salutations is the addition of the phrase omugorogoro/inzala yonyene i.e. 'apart from hunger (we are otherwise fine)' or, omugorogoro nikwo okululle i.e. '...hunger alone is the one devastating (us)'. These phrases are suggestive of the need to be provided with alms in form of food or cash. Thus, unlike in the past when people (including orphans, and the physically and psychologically challenged) were expected to offer menial jobs in order to be given food, nowadays, blatant begging has become the norm.

The term okhusuma has also now been redefined to include highly imbalanced relationships that clearly manifest market features. It is now used interchangeably with okhurunda, a term that refers to purchasing foodstuff (mainly cereals) at the market place - an activity that is basically performed by women. In this regard, okhusuma is gradually acquiring characteristics of impersonal relations that are strongly founded on economic benefits, which is the anti-thesis of its initial spirit. Secondly, although still upholding personal features in the sense that one can conveniently visit a kinsperson or friend in anticipation, other okhusuma relationships lack the labour component, as food may be given in spite of no work having been done for the provider. In other cases, visits would be done to relatives in areas considered resourceful in food, such as 
the maize breadbaskets of Trans-nzoia, Uasin Gishu and Lugari. Here, those coming okhusuma would be involved in paid labour, at the end of which they would purchase foodstuff to return with home.

In the very extreme extent, deficiency in food has now become a catalyst to other vices that border on the criminal and the tabooed. The socially acceptable measures of adaptation such as okhusuma (in whichever form), or even okhusaba are now giving in to theft (okhuiba) and robbery (okhunula). Deviant activities, particularly theft and robbery, pose the greatest security challenges for the administration in Bunyore and luhyialand. Marauding gangs, such as the dreaded msumbiji (Mozambique) that are common in western Kenya, are some of the widely quoted known by-products of a sustained situation of food deprivation. To most informants, factors associated with criminal activities such as poverty or learnt behaviour, are merely residual. In fact, they should all be encapsulated in one term: inzala munda; literally, 'hunger in the stomach'. To them, hunger drives people to seek all ways, criminal or not, of acquiring food.

Okhuiba (theft) and okhunula (robbery) are now taking new dimensions that were previously unheard of. For example, in the traditional life of the Abaluhyia, theft of food crops in the farms was an unthinkable act. Strong social sanctions were put in place against actions of this nature. For one reason or another, it was for instance taboo to steal food items such as eggs and pumpkins. According to informants, now, thievery of this calibre is becoming commonplace. For this reason, a number of farmers remove crops from the shambas prematurely for fear of losing them to thieves.

The foregoing discussion therefore reveals that the sustained experiences of seasonal hunger witnessed among the Abaluhyia, are a threat to positive values and tenets entrenched in their social fabric. Being a physiological want that cannot be repressed beyond a certain point, hunger must find satisfaction. The frequent incidences on the occurrences of hunger have resulted into new forms of adaptation aimed at satisfying this need. The traditional forms of adaptation are increasingly being rendered obsolete, paving way to emergent traits, a number of them that are seen to contradict conventional behavioural patterns.

\section{CONCLUSIONS}

The results of this study indicate that while the study population, the Abanyole, have had a long association with cases of famine and intermittent hunger, seasonal hunger, a trait of the deprivation that is predictable and that occurs on particular periods in an agricultural calendar, is a much more recent phenomenon. Issues to do with small landholdings, heavy population density, and poor economic entitlements are some of the key factors behind the food tribulations faced by Abanyole and other Abaluhyia sub-groups. The study also found out that as a result of the sustained experiences of food deprivation in Bunyore, hunger has generally been accepted as a destiny by a significant number of Abanyole and seemingly, being institutionalized and normalized within the social body. In line with Oscar Lewis's "culture of poverty" among slum-dwellers, in Bunyore, the study witnessed an emerging cultural configuration with behavioural patterns that are distinct from the conventional norms, and which may be associated with hunger. This paper argues that although culture is assigned an "inert" and "inconsequential" status to the extent that it is perceived not to bear any impact on the instrumental lives of a given people, the Abanyole example demonstrates that when members of society institutionalize and consider themselves destined to hunger, a resulting apathetic and fatalistic attitude may render them to be devoid of entrepreneurial spirit. The findings therefore validate an assumption in the study that constant episodes of seasonal hunger has conditioning effects on the adaptive capacity of the culture of a people, to the extent 
that emergent traits are now being entrenched in a new dynamic process, tending to replace earlier forms.

\section{Notes}

i The sub-tribes of the Abaluhyia include Marama, Kisa, Batsotso, Isukha, Idakho, Banyore, Wanga, Masaaba, Kabras, Tachoni, Tiriki, Maragoli, Samia, Marachi, Banyala, Bakhayo, Bukusu and Gisu. Earlier studies, however, fused the Tachoni within the Kabras sub-tribe.

ii Popular containers were those that were previously used for keeping Kimbo and Cowboy commercial cooking fats.

\section{References}

Boas, Franz. The Mind of Primitive Man, Macmillan, New York, 1911

Bradley, H. Fractured Identities: Changing Patterns of Inequality, Polity Press, Cambridge 1996

Dreze J. and Sen A. Hunger and Public Action, Clerandon, Oxford, 1989

Etambale, B.B.A., Olukoye G., Olubayo, Ambetsa J. Emuhaya Strategic Development Plan 2008-2018, 2008

FAO. The State of Food and Agriculture 2012, FAO, Rome, 2012

Frankenberger, T. and Goldstein, D. Coping Strategies for Small Farm Households. Association of Framing Systems Research Extension (AFRESE) Newsletter 1:1. 1980

Harris M. The Rise of Anthropological Theory: A History of Theories of Culture, Crowell, New York, 1911

Jenkins, R. Social Identity, London and Routledge, New York, 2008

Maxon, Robert. Going their separate ways: Agrarian Transformations in Kenya, Rosemont Publishing, Madison, 2003

Oscar Lewis. Anthropological Essays, Random House, New York, 1966

Wagner, G. The Changing Family Among the Bantu Kavirondo, Oxford University, London, 1949

Walker, P. Famine and Early Warning Systems, Earthscan, London, 1989

Wandere, Donald. Effects of Seasonal Hunger on Socio-cultural Value Systems The case of Abanyole of Western Kenya, Scholars, Saarbrucken, 2014

Watts, M. Copping with the Market: Uncertainty and Food Security among Hausa Peasants. In I. de Garrine and G. A Harrison (Eds.) Copping with Uncertainty in Food Supply Clarendon, Oxford, 1988

Were, Gideon S. A History of the Abaluyia of Western Kenya, East African Publishing House Nairobi, 1967

William Thomas. Definition of Situation. In L. Coser and B. Rosenberg (Eds.)Sociological Theory: A Book of Readings, New York, McMillan, 1969 